\title{
Effects of an exercise and hypocaloric healthy eating intervention on indices of psychological health status, hypothalamic-pituitary-adrenal axis regulation and immune function after early-stage breast cancer: a randomised controlled trial
}

John M Saxton ${ }^{*}$, Emma J Scott ${ }^{2}$, Amanda J Daley ${ }^{3}$, M Nicola Woodroofe $^{4}$, Nanette Mutrie ${ }^{5}$, Helen Crank ${ }^{6}$, Hilary J Powers ${ }^{7}$ and Robert E Coleman ${ }^{8}$

\begin{abstract}
Introduction: Many women experience emotional distress, depression and anxiety after a diagnosis of breast cancer. Psychological stress and depression have been associated with hypothalamic-pituitary-adrenal (HPA) axis dysregulation that may adversely affect immune system functioning and impact upon survival. This study investigated the effects of a lifestyle intervention on indices of psychological health status, HPA axis regulation and immune function in overweight women recovering from early-stage breast cancer treatment.

Methods: A total of 85 women treated for breast cancer 3 to 18 months previously were randomly allocated to a 6-month exercise and hypocaloric healthy eating program plus usual care or usual care alone (control group). Women in the intervention group received three supervised exercise sessions per week and individualized dietary advice, supplemented by weekly nutrition seminars. Depressive symptoms (Beck Depression Inventory version II: BDI-II), perceived stress (Perceived Stress Scale: PSS), salivary diurnal cortisol rhythms; inflammatory cytokines (IL-6 and Tumor necrosis factor-a), leukocyte phenotype counts, natural killer (NK) cell cytotoxicity and lymphocyte proliferation following mitogenic stimulation were assessed at baseline and 6-month follow up.

Results: Compared with the control group, the intervention group exhibited a reduction in depressive symptoms (adjusted mean difference, 95\% confidence intervals $(95 \% \mathrm{Cl}):-3.12,-1.03$ to $-5.26 ; P=0.004$ ) at the 6 -month follow-up but no significant decrease in PSS scores $(-2.07,-4.96$ to $0.82 ; P=0.16)$. The lifestyle intervention also had a significant impact on diurnal salivary cortisol rhythm compared with usual care alone, as evidenced by an increase in morning salivary cortisol at the 6 -month follow-up $(P<0.04)$, indicating a change in HPA axis regulation. Women in the control group had higher total leukocyte, neutrophil and lymphocyte counts in comparison to the intervention group at the 6-month follow-up $(P \leq 0.05)$, whereas there was no difference in NK cell counts $(P=0.46)$, NK cell cytotoxicity $(P=0.85)$ or lymphocyte proliferation responses $(P=0.11)$ between the two groups. Conclusion: Our results show that the lifestyle intervention resulted in a reduction in depressive symptoms and a normalisation of HPA axis regulation. Such changes could have important implications for long-term survival in women recovering from early-breast cancer treatment.
\end{abstract}

Trial registration: Current Controlled Trials: ISRCTN08045231

\footnotetext{
* Correspondence: john.saxton@uea.ac.uk

'School of Rehabilitation Sciences, Faculty of Medicine and Health Sciences,

Room 2-8 Queen's Building, University of East Anglia, Norwich NR4 7TJ,

United Kingdom

Full list of author information is available at the end of the article
} 


\section{Introduction}

Many women experience emotional distress, depression and anxiety after a diagnosis of breast cancer, which can persist for prolonged periods, irrespective of the clinical treatment outcome $[1,2]$. Studies show that a quarter of breast cancer patients have clinically important levels of emotional distress up to 12 months after treatment [3] and almost $50 \%$ of women experience depression and/or anxiety during this period [1]. Psychological stress and depression have been associated with hypothalamicpituitary-adrenal (HPA) axis dysregulation in breast cancer survivors, including aberrations in diurnal cortisol rhythm [4,5], and elevated levels of the inflammatory cytokine IL-6 [6] that may impair immune system functioning [7] and adversely impact upon survival [8,9].

The importance of healthy lifestyle behaviours to prevent the adverse effects of weight gain after a breast cancer diagnosis is widely acknowledged and sustainable lifestyle change was recently identified as one of the key areas for future research [10]. Lifestyle interventions that incorporate exercise and healthy eating advice could also have an important role in modulating indices of psychological health status during the early recovery phase after breast cancer treatment. Physical inactivity and poor dietary habits are independently associated with depressive symptoms in breast cancer survivors [11,12], whereas evidence suggests that regular exercise [13] and positive dietary change [14] can improve depressive symptoms and psychological wellbeing. By improving psychological health status, lifestyle interventions have the potential to impact upon the HPA axis regulation and enhance immune function in women recovering from breast cancer treatment. This could improve long-term outcome, as restoration of immune function after treatment is predictive of survival $[15,16]$.

We recently reported the results of a randomised controlled trial that investigated the effects of an exercise and hypocaloric healthy eating intervention on body weight and metabolic biomarkers associated with disease recurrence in women recovering from early-stage breast cancer treatment [17]. Women in the intervention group experienced a wide range of health benefits, including reductions in central adiposity, dietary fat intake, total cholesterol and resting diastolic blood pressure and an improvement in cardiopulmonary fitness [17]. Here, in the same patient cohort, we report the effects of the lifestyle intervention on indices of psychological health status, HPA axis regulation and immune function.

\section{Methods}

\section{Participant recruitment}

This study recruited 90 overweight women with a body mass index $(\mathrm{BMI})>25 \mathrm{~kg} / \mathrm{m}^{2}$, who had completed surgery, chemotherapy and radiotherapy for early-stage breast cancer (stage I to III) 3 to 18 months previously. Biological samples were unavailable for five women in the sample population, leaving an evaluable sample size of 85 women. Patients receiving adjuvant endocrine treatments were eligible, and those yet to complete a one-year course of adjuvant trastuzumab were also included, subject to acceptable cardiac function determined by a multi-gated acquisition (MUGA) scan and consultant approval. Exclusion criteria included: concomitant hormone replacement therapy (HRT) or oral contraceptives; metastatic or active loco-regional disease; physical or psychiatric impairment limiting physical mobility; severe nausea, anorexia or other conditions precluding participation in exercise, the consumption of alternative/complementary diets or use of high-dose antioxidant supplements; and those already engaged in regular exercise. Patients were recruited from the Cancer Clinical Trials Centre at Weston Park Hospital, Sheffield UK or through local cancer support services, the local media or word of mouth. Ethics approval was obtained from the South Sheffield Research Ethics Committee and all participants provided written informed consent prior to the first assessment visit.

\section{Sample size}

Change in body weight was chosen as the primary outcome variable for calculation of sample size [17]. Using the data of Utter et al. [18], we estimated that recruitment of 90 women (45 in each group) would give us $90 \%$ power to detect a clinically meaningful reduction in body weight between the groups at the two-sided $\alpha$ level of 0.05 . In addition, using Beck Depression Inventory II (BDI-II) data from our previous exercise trial [13], a sample size of 38 patients per group gave us $80 \%$ power to detect a change in BDI of 6 points at the alpha level of 0.05 .

\section{Randomisation and allocation concealment}

Following the assessment of outcome variables at baseline, patients were randomly allocated to one of two groups: (i) lifestyle intervention $(n=44)$, or (ii) control group $(n=41)$. The control group received a healthy eating booklet, Eat Well (Food Standards Agency, UK), which also included brief advice on keeping active. Minimisation was used to balance the potentially confounding variables of chemotherapy and treatment with tamoxifen, aromatase inhibitors or no hormone therapy. Randomisation was performed by an independent researcher at the Clinical Trials Research Unit, University of Leeds. The randomisation sequence was not disclosed until patients had completed their baseline assessments.

\section{Lifestyle intervention}

Details of the pragmatic lifestyle intervention were published previously [17]. Briefly, the 24-week lifestyle 
intervention combined three supervised exercise sessions each week with an individually tailored hypocaloric healthy eating programme. Exercise sessions (including one to three women) comprised 30 minutes of aerobic exercise (65 to $85 \%$ age-predicted maximum heart rate) using one or more of a treadmill, cross-trainer, cycle ergometer and/or rowing ergometer, followed by 10 to 15 minutes of muscle strengthening exercises using resistance bands, hand weights and stability balls. Each participant also received one-to-one individualized dietary advice and written information (Weight Loss On $A$ Plate, Scottish Dietetic Association). The written information included guidance on portion sizes for common foods in each food group and a healthy eating plan. The goal was to reduce the patient's total daily calorie intake to $600 \mathrm{kcal}$ below their calculated energy requirements, thereby inducing an estimated steady weight loss of up to $0.5 \mathrm{~kg}$ each week. Additional weekly small-group nutrition education seminars included topics such as dietary fat intake, hydration, achieving a healthy balanced diet and alcohol consumption. In the control group, contact with researchers was limited to assessment sessions. Participants in the control group were offered three exercise sessions at the university exercise research facility and general exercise and dietary advice after the final follow-up.

\section{Outcome measures}

Outcomes were assessed at baseline (pre-randomisation) and at 24 weeks post randomisation in both groups. Questionnaire outcomes (depressive symptoms and perceived stress) were assessed by a trained technician who was blinded to the group allocation. Saliva and blood analytes were measured blindly by members of the research team.

\section{Depressive symptoms and perceived stress}

Depressive symptoms were assessed using the BDI, Version $\mathrm{II}^{\odot}$ (BDI-II) [19], which has a range of 0 to 63, with each item rated on a 4-point Likert-type scale ranging from 0 to 3. Perceived stress was assessed using the perceived stress scale (PSS) [20]. The scale was developed to measure the extent to which respondents appraise situations in their life to be stressful during the past month. The 14-item scale has a range of 0 to 56 , with items rated on a Likert-type scale ranging from 0 to 4 , and with higher scores indicating higher levels of perceived stress.

\section{Saliva and blood analysis}

Saliva samples were collected using salivettes ${ }^{\circledR}$ (Sarstedt, Leicester, UK) containing a piece of absorbance gauze, at 8 am, 12 noon, $5 \mathrm{pm}$ and $9 \mathrm{pm}$ over three consecutive days and stored at $4^{\circ} \mathrm{C}$ until collection. Saliva samples from each daily time point were pooled and mixed, before being cleared by centrifugation at $300 \mathrm{~g}$ for $10 \mathrm{mi}$ nutes and stored for later analysis. Blood (15 to $20 \mathrm{~mL}$ ) was drawn from an antecubital vein between 8 and 10 am following a 12-hour overnight fast. Saliva samples for analysis of diurnal cortisol rhythms and serum samples for analysis of inflammatory cytokines (IL-6 and TNF- $\alpha$ ) were stored at $-80^{\circ} \mathrm{C}$ until analysis, with duplicate baseline and post-intervention samples analysed in the same batch. Analysis of lymphocyte phenotype and function ( $\mathrm{T}$ cell/natural killer (NK) cell phenotyping, lymphocyte proliferation in response to phytohemagglutinin (PHA) stimulation and NK cell cytotoxicity) were commenced within 2 hours of blood collection and analysed in duplicate or triplicate. Full blood-count analyses were undertaken in the Haematology Department of the Sheffield Teaching Hospitals NHS Foundation Trust UK. All other analyses were undertaken in the Biomedical Research Centre Laboratory at Sheffield Hallam University UK, as described below.

\section{HPA axis modulation}

Diurnal salivary cortisol concentrations were determined using a high sensitivity ELISA kit (Salimetrics, Newmarket, UK). The detection limit is $0.003 \mu \mathrm{g} / \mathrm{dL}$ and the intra- and inter-assay coefficients of variation were 3.5\% and $5.1 \%$, respectively. Salivary cortisol typically shows a diurnal response, being higher in the morning and lower in the evening. Hence, the area under the diurnal salivary cortisol curve (AUC) was calculated using the trapezoidal rule. The inflammatory cytokines, IL-6 and TNF- $\alpha$, were measured using high-sensitivity ELISA kits (R\&D Systems, Oxon, UK). The inter- and intraassay precision was $7.8 \%$ and $7.4 \%$, respectively for IL6 and $8.4 \%$ and 5.3\%, respectively for TNF- $\alpha$. The lower limits of detection were $0.039 \mathrm{pg} / \mathrm{mL}$ and $0.106 \mathrm{pg} / \mathrm{mL}$, respectively.

\section{Lymphocyte phenotyping}

Absolute counts of helper/inducer $\left(\mathrm{CD}^{+} \mathrm{CD}^{+}\right)$and suppressor/cytotoxic $\left(\mathrm{CD}^{+} \mathrm{CD}^{+}\right) \mathrm{T}$ lymphocytes and NK cells $\left(\mathrm{CD}^{-} \mathrm{CD} 16^{+} \mathrm{CD} 56^{+}\right)$were determined using a three-colour whole-blood staining technique (TriTest ${ }^{\mathrm{Tm}}$ BD Biosciences, Oxon, UK). Briefly, whole blood (100 $\mu \mathrm{l})$ was incubated for 30 minutes at $4^{\circ} \mathrm{C}$ with $10 \mu \mathrm{l}$ of TriTest $^{\text {TM }}$ solution (three-colour direct immunofluorescence reagent) in TruCount ${ }^{\mathrm{TM}}$ tubes containing a predefined number of lyophilized latex beads (BD Biosciences, Oxon, UK), before the erythrocytes were lysed and the sample analysed immediately using flow cytometry (FAC-Sort flow cytometer with CELLQuest Pro data acquisition and analysis software; BD Biosciences, Oxon, UK). 


\section{NK cell cytotoxicity}

Details of the NK cell cytotoxicity assay have been published previously [21]. Briefly, K562 cells (NK cellsensitive human erythroleukemic cell line) were grown in RPMI 1640 (Gibco-BRL, UK), supplemented with $100 \mu \mathrm{g} / \mathrm{mL}$ streptomycin, $100 \mathrm{U} / \mathrm{mL}$ penicillin and $10 \%$ fetal bovine serum (complete RPMI: cRPMI), before being labelled with the green fluorescent 3,3'-dioctadecyloxacarbocyanine perchlorate (DIOC18 $8_{(3)}$, Sigma-Aldrich Ltd., Dorset, UK) at a concentration of $3 \mathrm{mM}$ in dimethyl sulfoxide (DMSO). Unfractionated peripheral blood mononuclear cells (PBMCs) were used as the effector cell population. Peripheral blood was diluted 1:1 with $0.9 \% \mathrm{w} / \mathrm{v} \mathrm{NaCl}$ and two volumes of the diluted sample were layered over one volume of Nycoprep 1.077 (Axis-Shield Diagnostics Ltd., Huntingdon, UK). The gradient mixture was centrifuged at $300 \mathrm{~g}$ for 30 minutes and the PBMCs harvested from the interface. PBMCs were then resuspended in cRPMI $\left(5 \times 10^{6}\right.$ cells $\left./ \mathrm{mL}\right)$ prior to their inclusion as effector cells in the NK cell cytotoxicity assay. PBMC effector cells and $\mathrm{DIOC} 18_{(3)^{-}}$ labelled K562 target cells were mixed together at five effector:target (E:T) cell ratios: 50:1, 25:1, 12.5:1, 6.25:1 and 3.12:1, mixed thoroughly, pelleted by centrifugation at $300 \mathrm{~g}$ for 1 minute and incubated for 3 hours at $37^{\circ} \mathrm{C}$ in $5 \% \mathrm{CO}_{2} / 95 \%$ air in a humid environment. The DNA stain propidium iodide (PI; $10 \mu \mathrm{g} / \mathrm{mL}$ ), used to label non-viable cells, was then added immediately prior to flow cytometry analysis for determination of the proportion of live and dead K562 target cells at each E:T cell ratio.

\section{Lymphocyte proliferation assay}

Lymphocyte proliferation was measured using bromodeoxyuridine (BrdU) incorporation during DNA synthesis [22] after stimulation with the non-specific mitogen PHA. PBMCs $\left(50 \mu \mathrm{l}\right.$ of a $5 \times 10^{6}$ cells $/ \mathrm{mL}$ suspension in cRPMI) were added to the wells of a 96-well flat-bottom tissue microtitre plate before mixing with $50 \mu \mathrm{l}$ of PHA at concentrations of $0 \mu \mathrm{g} / \mathrm{mL}$ (culture medium only), $0.1,0.5,1.0$ and $10.0 \mu \mathrm{g} / \mathrm{mL}$ in cRPMI (final volume of $100 \mu \mathrm{l}$ per well). Cultures (in triplicate) were incubated at $37^{\circ} \mathrm{C}$ with $5 \% \mathrm{CO}_{2}$ for 48 hours and proliferation was assessed using a colorimetric BrdU immunoassay (BrdU Cell Proliferation ELISA: Roche Diagnostics GmbH, Mannheim, Germany). The mean optical density of antigen-stimulated cultures/mean optical density of medium-only cultures was determined for each culture treatment and recorded.

\section{Data analysis}

Intention-to-treat analysis was used to compare patients in the groups to which they were randomly assigned, with missing data being imputed using the SPSS linear interpolation procedure. Three women were lost to follow up in each group. The Shapiro Wilk test was used to check the normality of the data prior to data analysis, with non-normally distributed variables log-transformed to normality before analysis. Comparisons between the groups were analysed using analysis of covariance (ANCOVA), with baseline values used as the covariate. Repeated measures ANOVA was used to assess for changes from baseline within the groups. Unless otherwise stated, normally-distributed data are presented as mean \pm SD and non-normally distributed data as median (semi-interquartile range (SIQR)). Categorical data were analysed using the chi-squared test $\left(\chi^{2}\right)$. Statistical significance throughout was taken at the two-sided 5\% level $(P<0.05)$. All data were analysed using SPSS v19.0 (IBM, Somers, NY, USA).

\section{Results}

The two groups were generally well-matched at baseline for key demographic and anthropometric variables (Table 1). In addition, levels of depression and perceived stress were well-balanced across the two groups. Nearly all the women were white Caucasian and on average, were 7 to 9 months post-treatment. Compliance to the supervised exercise sessions was excellent, with women attending on average $84 \%$ (42 to $98 \%$ ) of the sessions that were offered to them.

Depressive symptoms were reduced in the intervention group in comparison with controls at the 6-month follow-up $(P=0.004)$. This was due to a greater reduction in BDI-II scores from baseline in the intervention group $(P<0.001)$ in comparison with the controls $(P=$ 0.02 ; Table 2). A total of 15 (34\%) of participants in the intervention group were at least mildly depressed at baseline (BDI-II $\geq 14$ [19]), in comparison with 2 participants $(4.5 \%)$ at the 6-month follow-up, whereas in the control group the number of at least mildly depressed participants remained constant (22\%) throughout the study period $\left(X^{2}=5.93 ; P=0.02\right)$. In contrast, the reduction in PSS score in the intervention group versus controls at the 6-month follow-up was not significant $(P=$ $0.16)$, despite a significant reduction from baseline PSS score $(P<0.001$, Table 2$)$.

A pronounced diurnal cortisol rhythm was evident at baseline in both groups, with highest levels being recorded in the morning sample and lowest values in the evening (Figure 1). Although a similar diurnal cortisol rhythm was apparent in both groups at the 6-month follow-up, an increase in diurnal salivary cortisol rhythm AUC was observed in the lifestyle intervention group in comparison with the controls $(P=0.03$; Figure 2$)$. This was attributable to a higher post-intervention morning salivary cortisol concentration $(P=0.03$; Figure 1$)$. In contrast, the lifestyle intervention had no effect on 
Table 1 Baseline characteristics of the two groups

\begin{tabular}{|c|c|c|}
\hline Characteristic & Intervention group $(n=44)$ & Control group $(n=41)$ \\
\hline Age, years & $55.8(10.0)$ & $55.3(8.8)$ \\
\hline Body mass, kg & $78.1(10.1)$ & $82.9(17.0)$ \\
\hline Body mass index, $\mathrm{kg} / \mathrm{m}^{2}$ & $29.7(3.5)$ & $31.1(5.7)$ \\
\hline Waist circumference, $\mathrm{cm}$ & $91.1(9.9)$ & $94.5(13.8)$ \\
\hline Waist:hip ratio & $0.82(0.07)$ & $0.83(0.06)$ \\
\hline Months post treatment & $9.0(5.5)$ & $7.1(4.4)$ \\
\hline Lymphoedema, n (\%) & $9(20.4)$ & $15(36.6)$ \\
\hline \multicolumn{3}{|l|}{ Ethnicity } \\
\hline White, n (\%) & $43(98)$ & $41(100)$ \\
\hline \multicolumn{3}{|l|}{ Marital status } \\
\hline Married/cohabitating, n (\%) & $29(66)$ & $29(71)$ \\
\hline Single/windowed/divorced, n (\%) & $15(34)$ & $12(29)$ \\
\hline Smokers, n (\%) & $3(6.8)$ & $1(2.4)$ \\
\hline \multicolumn{3}{|l|}{ Hormone treatment } \\
\hline Chemotherapy, n (\%) & $26(59.1)$ & $22(53.7)$ \\
\hline Radiotherapy, n (\%) & $38(86.4)$ & $33(80.5)$ \\
\hline Tamoxifen, n (\%) & $21(47.7)$ & $21(51.2)$ \\
\hline Arimidex, n (\%) & $14(31.8)$ & $10(24.4)$ \\
\hline Herceptin, n (\%) & $3(6.8)$ & $5(12.2)$ \\
\hline
\end{tabular}

n, number.

circulating levels of the inflammatory cytokines, IL-6 $(P=0.93)$ or TNF- $\alpha(P=0.61$; Table 2$)$.

An increase in total leukocyte count in the controls in comparison with the intervention group was observed at the 6-month follow-up $(P=0.04$; Table 3$)$, attributable to an increase in lymphocyte count $(P=0.04)$ and neutrophil count $(P=0.05)$. The $\mathrm{CD}^{+} \mathrm{CD}^{+}$and $\mathrm{CD}^{+}$ $\mathrm{CD}^{+} \mathrm{T}$ cell counts showed a different pattern of response between the two groups $(P \leq 0.05$; Table 3$)$. However, the lifestyle intervention had no effect on $\mathrm{CD} 4^{+}: \mathrm{CD} 8^{+}$ T cell ratio $(P=0.87)$, NK cell count $(P=0.46)$, NK cell cytotoxicity $(P=0.85)$ or lymphocyte proliferation in response to PHA stimulation $(P=0.11$; Table 3 and Figure 2).

\section{Discussion}

Although pragmatic lifestyle interventions could be important for helping to prevent the adverse effects of weight gain after breast cancer treatment [10], few studies have assessed the impact of combined exercise and healthy eating programmes on psychological wellbeing and associated prognostic biomarkers in breast cancer survivors [23,24]. This is the first study to report the effects of a combined exercise and healthy eating intervention on psychological health status, indices of HPA axis regulation and immune function in overweight women during the early recovery phase (3 to 18 months) after stage-I to -III breast cancer treatment. There was excellent compliance with the exercise sessions (84\%) and low attrition, with only three participants from each group being lost to follow up in this analysis of psychological and neuro-immunological variables. An improvement in depressive symptoms in the intervention group was not accompanied by a significant reduction in perceived stress. However, the lifestyle intervention also had a significant impact on diurnal salivary cortisol rhythm, as evidenced by an increase in morning salivary cortisol at the 6-month follow-up.

At baseline, BDI-II depression scores in our patient cohort were consistent with previous studies of breast

Table 2 BDI-II and PSS scores at baseline and 6 months in the lifestyle intervention and usual care control groups

\begin{tabular}{|c|c|c|c|c|c|c|}
\hline & Int & roup & & & & \\
\hline & Baseline & Follow up & $\Delta$ & Baseline & Follow up & $\Delta$ \\
\hline BDI-II & $11.3(7.6)$ & $5.1(4.9)$ & $-6.1(6.9)^{* *}$ & $10.2(5.5)$ & $7.9(6.0)$ & $-2.3(5.8)^{*}$ \\
\hline PSS & $22.9(7.2)$ & $18.2(7.7)$ & $-4.8(7.9)^{* *}$ & $21.5(5.6)$ & $19.5(6.8)$ & $-1.9(6.8)$ \\
\hline
\end{tabular}

BDI-II, Beck depression inventory-II; PSS, perceived stress scale; $\Delta$, change from the baseline score; ${ }^{*} P<0.05$; ${ }^{* *} P<0.01$ in comparison with baseline (within groups). 


\section{6 month follow-up}
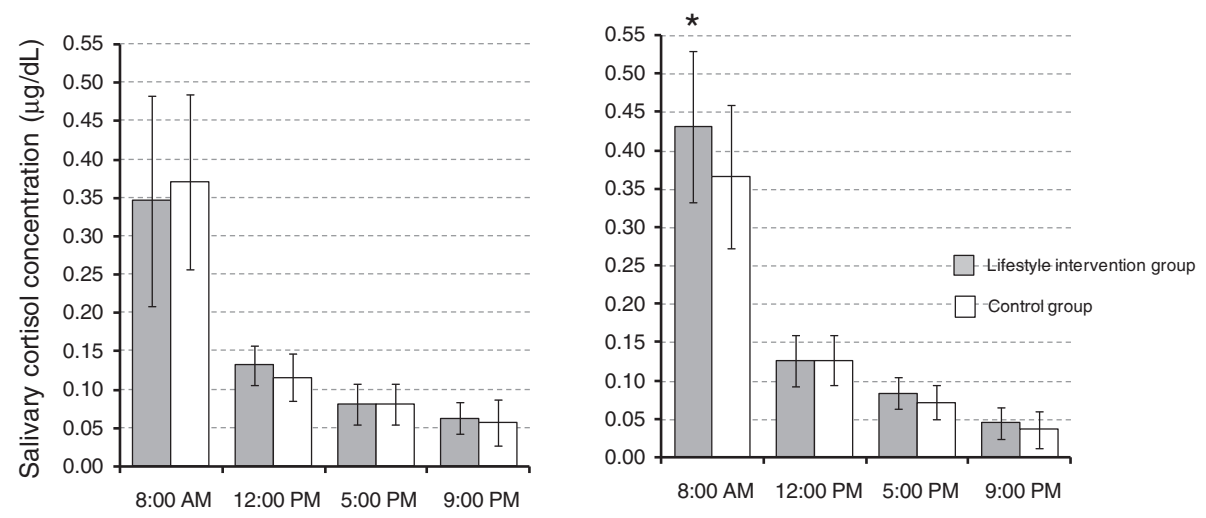

Figure 1 Diurnal salivary cortisol rhythm at baseline and 6-month follow-up. Values are medians with error bars representing semi-interquartile range $(\mathrm{SIQR}) .{ }^{*} P=0.03$ for area under the curve $(\mathrm{AUC})$ between groups.

cancer survivors $[2,11,25]$. Furthermore, the reduction in mean BDI-II depression score from baseline in the intervention group was similar to that previously reported following exercise interventions [25]. Improvements in depression scores have also been observed after lifestyle interventions involving a dietary component to promote healthy eating and healthy body weight maintenance $[26,27]$ but this has not been a consistent finding [23].
Using the criterion of $0.5 \mathrm{SD}$ for our sample population at baseline [28], a reduction in BDI-II score $>3$ points is clinically meaningful. Hence, the 6.1-point reduction from baseline and between-group difference of $>3$ points at the 6-month follow-up suggests that women in the intervention group experienced a clinically important change in depressive symptoms. Depressive symptoms in women recovering from breast cancer treatment have
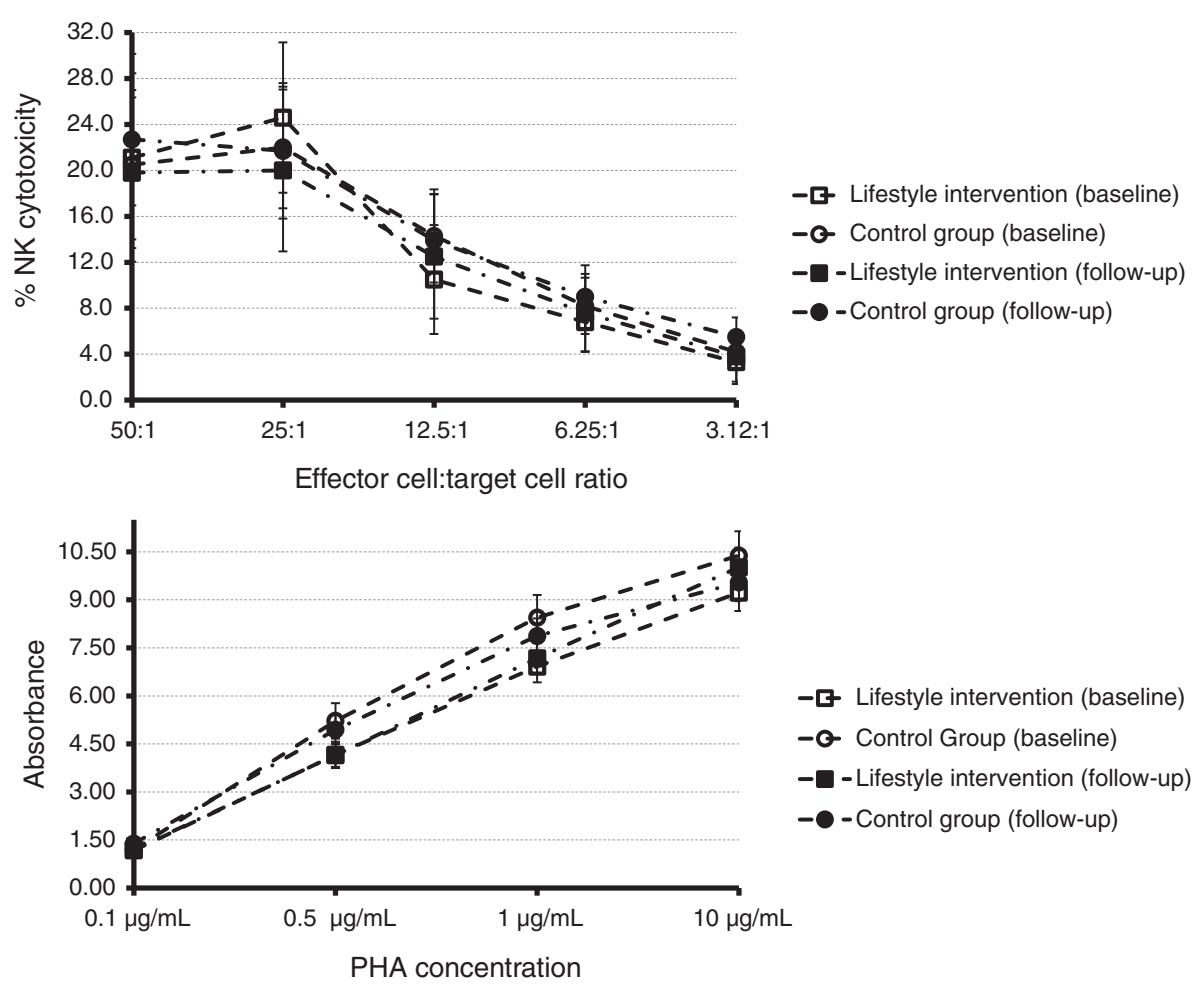

Figure 2 Natural killer (NK) cell cytotoxicity and lymphocyte proliferation at baseline and 6-month follow-up. Top, NK cell cytotoxicity at different effector: target cell ratios. Values are medians, with error bars representing semi-interquartile range (SIQR). Bottom, ILymphocyte proliferation responses. Values are means with error bars representing standard error of the mean. PHA, phytohemagglutinin. 
Table 3 Leukocyte counts and inflammatory cytokines at baseline and follow up

\begin{tabular}{|c|c|c|c|c|c|}
\hline & \multicolumn{2}{|c|}{ Intervention group } & \multicolumn{2}{|c|}{ Control group } & \multirow{2}{*}{$\begin{array}{c}P- \\
\text { value }\end{array}$} \\
\hline & Baseline & Follow up & Baseline & Follow up & \\
\hline \multicolumn{6}{|l|}{ Leukocyte counts } \\
\hline Total leukocyte count ( $10^{3}$ cells/ $\left./ \mu l\right)$ & $5.145(1.417)$ & $5.156(1.337)$ & $5.184(1.237)$ & $5.594(1.370)$ & 0.04 \\
\hline Neutrophil count $\left(10^{3}\right.$ cells/ $\left.\mu \mathrm{l}\right)$ & $3.014(1.119)$ & $2.958(1.135)$ & $3.131(0.912)$ & $3.377(1.061)$ & 0.05 \\
\hline Monoctye count $\left(10^{3}\right.$ cells/ul) & $0.400(0.370,0.430)$ & $0.4000 .360,0.440$ & $0.400(0.350,0.450)$ & $0.400(0.350,0.450)$ & 0.63 \\
\hline Lymphocyte count ( $10^{3}$ cells/ul) & $1.507(0.414)$ & $1.523(0.389)$ & $1.446(0.497)$ & $1.612(0.449)$ & 0.04 \\
\hline $\mathrm{CD}^{+} \mathrm{CD}^{+} \mathrm{T}$ cells $\left(10^{3} \mathrm{cells} / \mu \mathrm{l}\right)$ & $0.748(0.596,0.900)$ & $0.682(0.605,0.759)$ & $0.659(0.532,0.786)$ & $0.763(0.648,0.878)$ & 0.02 \\
\hline $\mathrm{CD}^{+} \mathrm{CD}^{+} \mathrm{T}$ cells $\left(10^{3}\right.$ cells $\left./ \mu \mathrm{l}\right)$ & $0.474(0.365,0.583)$ & $0.402(0.334,0.470)$ & $0.360(0.214,0.506)$ & $0.409(0.322,0.496)$ & 0.05 \\
\hline $\mathrm{CD}^{+}: \mathrm{CD}^{+}$ratio & $1.62(1.36,1.88)$ & $1.69(1.40,1.98)$ & $1.93(1.51,2.35)$ & $1.91(1.49,2.33)$ & 0.87 \\
\hline NK cells $\left(10^{3}\right.$ cells $\left./ \mu \mathrm{l}\right)$ & $0.200(0.175,0.225)$ & $0.206(0.177,0.235)$ & $0.176(0.147,0.205)$ & $0.174(0.144,0.292)$ & 0.46 \\
\hline \multicolumn{6}{|l|}{ Inflammatory cytokines } \\
\hline IL-6 (pg/mL) & $1.599(1.259,1.906)$ & $1.692(1.377,2.007)$ & $1.755(1.456,2.054)$ & $1.942(1.602,2.282)$ & 0.93 \\
\hline TNF- $a(\rho g / m L)$ & $0.889(0.779,0.999)$ & $0.916(0.767,1.065)$ & $1.058(0.895,1.221)$ & $0.992(0.870,1.114)$ & 0.61 \\
\hline
\end{tabular}

Data are presented as means (SD) or medians (semi-interquartile range). $P$-value shown for between-group comparisons. $P$-values in boldface significant at alpha 0.05. NK, natural killer.

been associated with fatigue, pain, sleep disturbances, low libido, poor financial status and social support, and a range of other psychological factors [2]. Physical inactivity and poor dietary habits have also been independently associated with depressive symptoms in breast cancer survivors $[11,12]$.

Evidence suggests that lifestyle interventions, which include support for exercise and dietary behaviour change, may improve depressive symptoms by improving mood, enhancing self-efficacy expectations, reducing intrusive thoughts about breast cancer and future morbidity/mortality and buffering self-concept perceptions $[27,29]$. Reductions in body weight and/or body fat and improvements in cardiopulmonary fitness (as observed in the intervention participants [17]) could also have a positive impact on depression scores [30,31]. In addition, biological mechanisms, including the release of monoamine neurotransmitters (that is, serotonin, dopamine and norepinephrine) and endorphins during exercise have been proposed to account for improvements in depressive symptoms in physically active individuals [32]. However, it is also important to be mindful of attention effects on depression symptoms, as an improvement in BDI-II score was previously reported in the attention control arm of a short-term exercise trial in a similar cohort of early-stage breast cancer patients [13]. The increased level of personal contact between the intervention group and researchers is a potential limitation of the present study, which needs to be taken into consideration. In summary, continued research is necessary to understand the extent to which such factors influenced the improvement in depressive symptoms in the present study and the impact of changes on longterm prognosis.
Although the intervention group also exhibited a significant reduction in PSS scores from baseline levels, the smaller difference between groups at the 6-month follow-up was not significant. PSS scores in our patient cohort at baseline were comparable to those reported previously for breast cancer survivors [33-37]. However, the lack of effect on this outcome measure contrasts with previously reported reductions (in the range of 4 to 9 points) following stress management and yoga interventions in early-stage breast cancer patients [33-36]. A large proportion of breast cancer survivors are reported to use complementary therapies (including exercise) to manage stress [38], but only one previous study has reported reductions in PSS scale scores following exercise training [37]. The reduction in PSS scores after a 10week programme of aerobic and resistance exercise was only marginally greater in this study than the nonsignificant difference between groups in our patient cohort at the 6-month follow-up. Hence, the lack of a significant effect on perceived stress in the present study may be a reflection of low statistical power for this outcome.

The intervention had a significant impact on HPA axis regulation, as evidenced by an increase in diurnal salivary cortisol rhythm at the 6-month follow-up. This was attributable to a higher morning salivary cortisol concentration. Cortisol levels follow a strong circadian rhythm in healthy adults, with the highest levels being evident in the morning after awakening and the nadir occurring at around midnight [39]. A pronounced diurnal cortisol rhythm was apparent at baseline in our patient cohort, and this is consistent with previous studies of non-metastatic breast cancer patients and survivors $[4,5]$. However, this is the first study to report a steepening 
of diurnal cortisol rhythm following a lifestyle intervention in breast cancer patients in the early recovery phase after treatment. The implications of this are difficult to define but flatter diurnal cortisol rhythms (blunted morning and/ or elevated evening levels) have been associated with depressive symptoms, poor sleep quality and persistent fatigue after breast cancer treatment [5,40]. Hence, the intervention may have influenced morning cortisol levels via its positive impact on one or all of these factors, or via its impact on other factors not monitored in this study. Interestingly, an increase in morning cortisol level, accompanied by improvements in depressive symptoms and psychological stress, was reported after an 8-week stress reduction programme involving yoga, meditation and group discussions in breast cancer patients [33]. This was interpreted as evidence that the intervention resulted in a normalisation of the cortisol response. In a similar way, our results may indicate a modest improvement in HPA axis regulation in the intervention group but further research is needed to confirm this and delineate the precise determinants of HPA axis modulation.

Circulating levels of the inflammatory cytokines IL-6 and TNF- $\alpha$ have also been used as evidence of aberrant HPA axis regulation in breast cancer patients and other populations $[6,7,9]$. Depression and psychological stress are characterised by elevated levels of IL- 6 and TNF- $\alpha$, $[6,41]$ and IL- 6 stimulates cortisol secretion by adrenocortical cells [42]. However, in the present study, levels of these inflammatory cytokines were unchanged at the 6-month follow-up, and this is consistent with previous lifestyle intervention studies involving breast cancer survivors [23,24]. Elevated levels of these inflammatory cytokines have more generally been associated with severe and/or chronic depression and more marked HPA axis dysregulation in previous studies [6,9]. The pronounced diurnal cortisol rhythm at baseline in our patient cohort, coupled with evidence of mild depressive symptoms, suggests a more modest disruption of HPA axis regulation, which probably explains why the intervention had no effect on these inflammatory cytokines.

This is also consistent with our results for immune function. Previous studies show that high levels of stress and depression, coupled with the persistent activation of the HPA axis, impair immune responses and potentially contribute to the development and progression of cancer (reviewed by Reiche et al. [7]). However, indices of immune function (lymphocyte proliferation and NK cell cytotoxicity) were unchanged from baseline levels in the present study. Furthermore, the different pattern of response in $\mathrm{CD}^{+} \mathrm{CD} 4^{+}$and $\mathrm{CD}^{+} \mathrm{CD} 8^{+} \mathrm{T}$ cell counts is difficult to interpret, as baseline values were higher in the intervention group. Nevertheless, an increase in total leukocyte count, attributable to an increase in lymphocyte and neutrophil counts, was observed in the controls. The clinical implications of the latter are unknown but surgically treated early-stage breast cancer patients who experienced disease recurrence exhibited higher lymphocyte and neutrophil counts relative to disease-free patients in the 17 months prior to recurrence detection [8]. This contrasts with earlier evidence of an association between low lymphocyte counts and breast cancer recurrence [43]. Although changes in circulating leukocyte counts during recovery from cancer treatment may be indicative of specific and/or non-specific immune reactions to sub-clinical disease $[8,43]$, the clinical significance of such changes in our patient cohort is difficult to interpret without the longerterm follow-up of clinical endpoints such as disease-free interval and mortality.

\section{Conclusions}

In conclusion, this study shows for the first time that an improvement in depressive symptoms resulting from supervised exercise and healthy eating advice in the early recovery phase, 3 to 18 months, after breast cancer treatment is accompanied by a significant change in diurnal salivary cortisol rhythm. The increase in morning salivary cortisol at the 6-month follow-up suggests a normalisation of HPA axis regulation, which may be linked to the improvement in psychological health status. The precise determinants and clinical significance of these changes warrants further investigation.

\section{Abbreviations \\ ANCOVA: analysis of covariance; ANOVA: analysis of variance; AUC: area under the curve; BDI-II: Beck depression inventory version II; BMI: body mass index; BrdU: bromodeoxyuridine; ELISA: enzyme-linked immunosorbent assay; E:T: effector:target; HPA: hypothalamic-pituitary-adrenal; HRT: hormone replacement therapy; IL-6: interleukin-6; MUGA: multi-gated acquisition; NK: natural killer; PBMC: peripheral blood mononuclear cell; PHA: phytohemagglutinin; PSS: perceived stress scale; SIQR: semi-interquartile range; TNF-a: tumour necrosis factor-alpha.}

\section{Competing interests}

The authors declare that they have no competing interests.

\section{Authors' contributions}

JMS was the project lead, had a substantial involvement in the concept and design, analysis of biological samples, data analysis, interpretation, and drafting the manuscript; EJS was the main researcher responsible for the delivery of the intervention, acquisition of data (including analysis of biological samples) and revised the manuscript for intellectual content; AJD had a significant involvement in the overall conception and design, data interpretation and critical revision of the manuscript; MNW had a significant involvement in conception and design, including the choice of biological outcomes, acquisition of biological data and critical revision of the manuscript; NM was involved in the conception and design, data interpretation, critical revision of the manuscript; $\mathrm{HC}$ was involved in delivering the intervention, data acquisition and critical revision of the manuscript; HJP was involved in the conception and design, data interpretation, critical revision of the manuscript; REC guided recruitment, advised on clinical issues and was also involved in the conception and design, data interpretation and critical revision of the manuscript. All authors read and approved the final manuscript.

\section{Acknowledgements}

We acknowledge the contributions of Helen Lloyd, Alayne Flowers and Alan Ruddock in carrying out the blinded assessments. This study was supported 
by a Project Grant from the American Institute for Cancer Research (Grant number 05A008-REV), awarded to JMS, AJD, MNW, NM, HJP and REC, which supported the direct costs of the research.

\section{Author details}

'School of Rehabilitation Sciences, Faculty of Medicine and Health Sciences, Room 2-8 Queen's Building, University of East Anglia, Norwich NR4 7TJ, United Kingdom. ${ }^{2}$ Warwick Medical School, University of Warwick, Coventry, UK. ${ }^{3}$ Department of Primary Care Clinical Sciences, University of Birmingham, Birmingham, UK. ${ }^{4}$ Biomedical Research Centre, Sheffield Hallam University, Sheffield, UK. ${ }^{5}$ Institute for Sport, Physical Education and Health Sciences, University of Edinburgh, Edinburgh, UK. ${ }^{6}$ Centre for Sport and Exercise Science, Sheffield Hallam University, Sheffield, UK. ${ }^{7}$ Human Nutrition Unit, Department of Oncology, University of Sheffield, Sheffield, UK. ${ }^{8}$ CR-UK/YCR Sheffield Cancer Research Centre, Weston Park Hospital, University of Sheffield, Sheffield, UK.

Received: 31 October 2013 Accepted: 25 March 2014 Published: 14 April 2014

\section{References}

1. Burgess C, Cornelius V, Love S, Graham J, Richards M, Ramirez A Depression and anxiety in women with early breast cancer: five year observational cohort study. BMJ 2005, 330:702.

2. Zainal NZ, Nik-Jaafar NR, Baharudin A, Sabki ZA, Ng CG: Prevalence of depression in breast cancer survivors: a systematic review of observational studies. Asian Pac J Cancer Prev 2013, 14:2649-2656.

3. Millar K, Purushotham AD, McLatchie E, George WD, Murray GD: A 1-year prospective study of individual variation in distress, and illness perceptions, after treatment for breast cancer. J Psychosom Res 2005, 58:335-342.

4. Porter LS, Mishel M, Neelon V, Belyea M, Pisano E, Soo MS: Cortisol levels and responses to mammography screening in breast cancer survivors: a pilot study. Psychosom Med 2003, 65:842-848

5. Hsiao FH, Chang KJ, Kuo WH, Huang CS, Liu YF, Lai YM, Jow GM, Ho RT, Ng SM, Chan CL: A longitudinal study of cortisol responses, sleep problems, and psychological well-being as the predictors of changes in depressive symptoms among breast cancer survivors. Psychoneuroendocrinology 2013, 38:356-366.

6. Soygur H, Palaoglu O, Akarsu ES, Cankurtaran ES, Ozalp E, Turhan L, Ayhan $\mathrm{H}$ : Interleukin-6 levels and HPA axis activation in breast cancer patients with major depressive disorder. Prog Neuropsychopharmacol Biol Psychiatry 2007, 31:1242-1247.

7. Reiche EM, Nunes SO, Morimoto HK: Stress, depression, the immune system, and cancer. Lancet Oncol 2004, 5:617-625.

8. Thornton LM, Andersen BL, Carson WE III: Immune, endocrine, and behavioral precursors to breast cancer recurrence: a case-control analysis. Cancer Immunol Immunother 2008, 57:1471-1481.

9. Spiegel D: Mind matters in cancer survival. Psychooncology 2012, 21:588-593.

10. Eccles SA, Aboagye EO, Ali S, Anderson AS, Armes J, Berditchevski F, Blaydes JP, Brennan K, Brown NJ, Bryant HE, Bundred NJ, Burchell JM, Campbell AM, Carroll JS, Clarke RB, Coles CE, Cook GJ, Cox A, Curtin NJ, Dekker LV, Silva Idos S, Duffy SW, Easton DF, Eccles DM, Edwards DR, Edwards J, Evans D, Fenlon DF, Flanagan JM, Foster C: Critical research gaps and translational priorities for the successful prevention and treatment of breast cancer. Breast Cancer Res 2013, 15:R92. doi:10.1186/bcr3493.

11. Yeter K, Rock CL, Pakiz B, Bardwell WA, Nichols JF, Wilfley DE: Depressive symptoms, eating psychopathology, and physical activity in obese breast cancer survivors. Psychooncology 2006, 15:453-462.

12. Hong S, Bardwell WA, Natarajan L, Flatt SW, Rock CL, Newman VA, Madlensky L, Mills PJ, Dimsdale JE, Thomson CA, Hajek RA, Chilton JA, Pierce JP: Correlates of physical activity level in breast cancer survivors participating in the Women's Healthy Eating and Living (WHEL) Study. Breast Cancer Res Treat 2007, 101:225-232.

13. Daley AJ, Crank H, Saxton JM, Mutrie N, Coleman R, Roalfe A: Randomized trial of exercise therapy in women treated for breast cancer. J Clin Oncol 2007, 25:1713-1721.

14. Maunsell E, Drolet M, Brisson J, Robert J, Deschenes L: Dietary change after breast cancer: extent, predictors, and relation with psychological distress. J Clin Oncol 2002, 20:1017-1025.
15. Levy SM, Herberman RB, Lippman M, D'Angelo T, Lee J: Immunological and psychosocial predictors of disease recurrence in patients with early-stage breast cancer. Behav Med 1991, 17:67-75.

16. Wiltschke C, Krainer M, Budinsky AC, Berger A, Muller C, Zeillinger R, Speiser P, Kubista E, Eibl M, Zielinski CC: Reduced mitogenic stimulation of peripheral blood mononuclear cells as a prognostic parameter for the course of breast cancer: a prospective longitudinal study. Br J Cancer 1995, 71:1292-1296.

17. Scott E, Daley AJ, Doll H, Woodroofe N, Coleman RE, Mutrie N, Crank H, Powers HJ, Saxton JM: Effects of an exercise and hypocaloric healthy eating program on biomarkers associated with long-term prognosis after early-stage breast cancer: a randomized controlled trial. Cancer Causes Control 2013, 24:181-191.

18. Utter AC, Nieman DC, Shannonhouse EM, Butterworth DE, Nieman CN Influence of diet and/or exercise on body composition and cardiorespiratory fitness in obese women. Int J Sports Nutr 1998, 8:213-222.

19. Beck AT, Steer R, Brown GK: Beck Depression Inventory (BDI-II). London: The Psychological Corporation; 1996. Copyright @ 1996Aaron T. Beck. Reproduced with permission of the publisher NCS Pearson, Inc. All rights reserved.

20. Cohen S, Kamarck T, Mermelsstein R: A global measure of perceived stress. J Health Soc Behav 1983, 24:386-396.

21. Piriou L, Chilmonczyk S, Genetet N, Albina E: Design of a flow cytometric assay for the determination of natural killer and cytotoxic T-lymphocyte activity in human and in different animal species. Cytometry 2000, 41:289-297.

22. Gratzner HG: Monoclonal antibody to 5-bromo- and 5-iododeoxyuridine: A new reagent for detection of DNA replication. Science 1982, 218:474-475.

23. Demark-Wahnefried W, Case LD, Blackwell K, Marcom PK, Kraus W, Aziz N, Snyder DC, Giguere JK, Shaw E: Results of a diet/exercise feasibility trial to prevent adverse body composition change in breast cancer patients on adjuvant chemotherapy. Clin Breast Cancer 2008, 8:70-79.

24. Pakiz B, Flatt SW, Bardwell WA, Rock CL, Mills PJ: Effects of a weight loss intervention on body mass, fitness, and inflammatory biomarkers in overweight or obese breast cancer survivors. Int I Behav Med 2011 18:333-341.

25. Craft LL, Vaniterson EH, Helenowski IB, Rademaker AW, Courneya KS: Exercise effects on depressive symptoms in cancer survivors: a systematic review and meta-analysis. Cancer Epidemiol Biomarkers Prev 2012, 21:3-19.

26. Kim SH, Shin MS, Lee HS, Lee ES, Ro JS, Kang HS, Kim SW, Lee WH, Kim HS, Kim CJ, Kim J, Yun YH: Randomized pilot test of a simultaneous stage-matched exercise and diet intervention for breast cancer survivors. Oncol Nurs Forum 2011, 38:E97-106.

27. Scheier MF, Helgeson VS, Schulz R, Colvin S, Berga S, Bridges MW, Knapp J, Gerszten K, Pappert WS: Interventions to enhance physical and psychological functioning among younger women who are ending nonhormonal adjuvant treatment for early-stage breast cancer. J Clin Oncol 2005, 23:4298-4311.

28. Copay AG, Subach BR, Glassman SD, Polly DW Jr, Schuler TC: Understanding the minimum clinically important difference: a review of concepts and methods. Spine J 2007, 7:541-546.

29. Rimer J, Dwan K, Lawlor DA, Greig CA, McMurdo M, Morley W, Mead GE: Exercise for depression. Cochrane Database Syst Rev 2012, 7, CD004366.

30. Kulie T, Slattengren A, Redmer J, Counts H, Eglash A, Schrager S: Obesity and women's health: an evidence-based review. J Am Board Fam Med 2011, 24:75-85.

31. Imayama I, Alfano CM, Kong A, Foster-Schubert KE, Bain CE, Xiao L, Duggan C, Wang CY, Campbell KL, Blackburn GL, McTiernan A: Dietary weight loss and exercise interventions effects on quality of life in overweight/obese postmenopausal women: a randomized controlled trial. Int J Behav Nutr Phys Act 2011, 8:118

32. Brown JC, Huedo-Medina TB, Pescatello LS, Ryan SM, Pescatello SM, Moker E, LaCroix JM, Ferrer RA, Johnson BT: The efficacy of exercise in reducing depressive symptoms among cancer survivors: a meta-analysis. PLoS One 2012, 7:e30955.

33. Matousek RH, Pruessner JC, Dobkin PL: Changes in the cortisol awakening response (CAR) following participation in mindfulness-based stress reduction in women who completed treatment for breast cancer. Complement Ther Clin Pract 2011, 17:65-70. 
34. Vadiraja HS, Raghavendra RM, Nagarathna R, Nagendra HR, Rekha M, Vanitha N, Gopinath KS, Srinath BS, Vishweshwara MS, Madhavi YS, Ajaikumar BS, Ramesh BS, Nalini R, Kumar V: Effects of a yoga program on cortisol rhythm and mood states in early breast cancer patients undergoing adjuvant radiotherapy: a randomized controlled trial. Integr Cancer Ther 2009, 8:37-46.

35. Loprinzi CE, Prasad K, Schroeder DR, Sood A: Stress Management and Resilience Training (SMART) program to decrease stress and enhance resilience among breast cancer survivors: a pilot randomized clinical trial. Clin Breast Cancer 2011, 11:364-368.

36. Banerjee B, Vadiraj HS, Ram A, Rao R, Jayapal M, Gopinath KS, Ramesh BS, Rao N, Kumar A, Raghuram N, Hegde S, Nagendra HR, Prakash Hande M: Effects of an integrated yoga program in modulating psychological stress and radiation-induced genotoxic stress in breast cancer patients undergoing radiotherapy. Integr Cancer Ther 2007, 6:242-250

37. Hughes DC, Leung P, Naus MJ: Using single-system analyses to assess the effectiveness of an exercise intervention on quality of life for Hispanic breast cancer survivors: a pilot study. Soc Work Health Care 2008, 47:73-91.

38. Hann D, Baker F, Denniston M, Entrekin N: Long-term breast cancer survivors' use of complementary therapies: perceived impact on recovery and prevention of recurrence. Integr Cancer Ther 2005, 4:14-20.

39. Heaney JL, Phillips AC, Carroll D: Aging, health behaviors, and the diurnal rhythm and awakening response of salivary cortisol. Exp Aging Res 2012, 38:295-314

40. Bower JE, Ganz PA, Dickerson SS, Petersen L, Aziz N, Fahey JL: Diurnal cortisol rhythm and fatigue in breast cancer survivors. Psychoneuroendocrinology 2005, 30:92-100.

41. Anderson $G$, Maes M, Berk M: Biological underpinnings of the commonalities in depression, somatization, and Chronic Fatigue Syndrome. Med Hypotheses 2012, 78:752-756.

42. Weber MM, Michl P, Auernhammer CJ, Engelhardt D: Interleukin-3 and interleukin-6 stimulate cortisol secretion from adult human adrenocortical cells. Endocrinology 1997, 138:2207-2210.

43. Pattison CW, Woods KL, Morrison JM: Lymphocytopenia as an independent predictor of early recurrence in breast cancer. Br J Cancer 1987, 55:75-76.

doi:10.1186/bcr3643

Cite this article as: Saxton et al: Effects of an exercise and hypocaloric healthy eating intervention on indices of psychological health status, hypothalamic-pituitary-adrenal axis regulation and immune function after early-stage breast cancer: a randomised controlled trial. Breast Cancer Research 2014 16:R39.

\section{Submit your next manuscript to BioMed Central and take full advantage of:}

- Convenient online submission

- Thorough peer review

- No space constraints or color figure charges

- Immediate publication on acceptance

- Inclusion in PubMed, CAS, Scopus and Google Scholar

- Research which is freely available for redistribution 